\title{
A study to evaluate the perinatal outcome in pregnancy induced hypertension
}

\author{
Tiwari $\mathbf{A}^{1}$, Dwivedi $\mathbf{R}^{2}$ \\ ${ }^{1}$ Dr Astha Tiwari, Assistant Professor, ${ }^{2}$ Dr Rinu Dwivedi, Assistant Professor, Department of Paediatrics, Chirayu \\ Medical College and Hospital Bhopal, MP, India.
}

Address for correspondence: Dr Astha Tiwari, Email: roshanchanchlani@gmail.com

\begin{abstract}
Introduction: Pregnancy-induced hypertension is the general classification for hypertension diseases during pregnancy, which include pregnancy-induced hypertension usually after $20^{\text {th }}$ week of gestation (without proteinuria), pre-eclampsia (with proteinuria), and eclampsia (pre-eclampsia with convulsions). This disease is responsible for high maternal and perinatal morbidity and mortality rates, and is one of the main public health problems. Material and Methods: It was retrospective study conducted between March 2013 to March 2016 in the department of pediatrics, Chirayu Medical College and hospital Bhopal. A total of 3015 mothers were delivered in department of obstetrics and gynecology. Out of these 180 were identified as having pregnancy induced hypertension. During the same period 100 mothers without any risk factor were included in the study. Results: Out of 180 cases of hypertensive disorders of pregnancy, majority were of preeclampsia (47.22\%), then Gestational hypertension $38.88 \%$, percentage of eclampsia (13.88\%). Incidence of Pregnancy Induced Hypertension- 5.97\%. Incidence of low birth weight in PIH is 57.7\%, preterm $44.2 \%$ and IUGR 20.4\%, Still birth 8 (4.4\%), early neonatal death 22 (12.2\%), Highest incidence of LBW (88\%), Preterm (80\%), IUGR $(12 \%)$ is present in eclampsia group. In control group incidence of LBW is $22 \%(\mathrm{P}<.001)^{* *}$, Prmaturity-18\% $(\mathrm{P}<.001)^{* *}$, IUGR-6\% $\mathrm{P}(<.05)^{*}$. Conclusion: The purpose of this article is to give overview of burden of adverse perinatal outcome in high risk Pregnancy. Thus High risk pregnancy should be identified prospectively and then given special care, perhaps a major impact on overall perinatal loss could be reduced.
\end{abstract}

Keywords: Antenatal, IUGR, Low birth weight, Pregnancy Induced Hypertension, Risk factors.

\section{Introduction}

Hypertension during pregnancy is a highly variable disorder unique to pregnancy and a leading cause of maternal and fetal/neonatal morbidity and mortality [1-4]. Pregnancy-induced hypertension is the general classification for hypertension diseases during pregnancy, which include pregnancy-induced hypertension usually after $20^{\text {th }}$ week of gestation (without proteinuria), pre-eclampsia (with proteinuria), and eclampsia (pre-eclampsia with convulsions). This disease is responsible for high maternal and perinatal morbidity and mortality rates, and is one of the main public health problems $[5,6]$. The most common consequences associated with hypertension diseases Intra-uterine fetal growth restriction (IUGR), intrauterine fetal demise and prematurity and low birth

Manuscript received: $24^{\text {th }}$ March 2016

Reviewed: $4^{\text {th }}$ April 2016

Author Corrected; $18^{\text {th }}$ April 2016

Accepted for Publication: $1^{\text {st }}$ May 2016 weight [6]. Antepartum diagnosis of mild, moderate, and severe preeclampsia is based on series of defined criteria occurring after 20 weeks of gestation [7]. Severe PE is defined as a blood pressure greater than $160 \mathrm{~mm} \mathrm{Hg}$ (systolic) or $110 \mathrm{~mm} \mathrm{Hg}$ (diastolic) associated with proteinuria greater than or equal to 5 grams per day. Furthermore, pre-eclampsia is regarded as severe in the presence of multiorgan involvement including thrombocytopenia (platelet count less than 100,000/ul), pulmonary edema, or oliguria (less than $500 \mathrm{ml}$ per day). In contrast, mild $\mathrm{PE}$ is characterized by an elevated blood pressure less than $160 \mathrm{~mm} \mathrm{Hg}$ (systolic) or $120 \mathrm{~mm} \mathrm{Hg}$ (diastolic) with proteinuria greater than $300 \mathrm{mg}$, but less than $5 \mathrm{~g}$, per day [8]. Ongoing debate on the optimal way to classify disease severity in preeclampsia is likely due to incomplete knowledge of the underlying pathophysiology of disorder, with the clinical and 
laboratory manifestations of preeclampsia representing a common endpoint for a variety of maternal disease states during pregnancy [9].

\section{Material and Methods}

Study design: Cohort study

Study period: March 2013 -to March 2016

Study place: The study was carried out in the department of pediatrics, Chirayu Medical College and Hospital Bhopal.
Study population: A total of 3015 mothers were delivered in department of obstetrics and gynecology, out of this 180 were identified as having pregnancy induced hypertension. During the same period 100 mothers without any risk factor were included in the study.

Procedure: The records of the study group were studied retrospectively and the high risk factors in the antenatal period and the fetal outcome were compared.

Statistical analysis: The data was entered in the Microsoft office excel 2007 and analyzed using Epiinfo software (available free online).

\section{Results}

Table No.1: Distribution of cases in Pregnancy induced Hypertension.

\begin{tabular}{|c|c|c|c|}
\hline \multirow{2}{*}{ Pregnancy induced Hypertension } & \multicolumn{2}{|c|}{ Total (n=180) } & \multirow{2}{*}{$\begin{array}{c}\text { Incidence } \\
\text { Total Deliveries }(\mathbf{n}=\mathbf{3 0 1 5})\end{array}$} \\
\cline { 2 - 3 } & $\mathbf{N o}$ & $\mathbf{\%}$ & $2.3 \%$ \\
\hline Gestational hypertension (GSHT) & 70 & 38.38 & $2.8 \%$ \\
\hline Preeclampsia & 85 & 47.22 & $0.82 \%$ \\
\hline Eclampsia & 25 & 13.88 & $5.97 \%$ \\
\hline Total & 180 & & \multirow{2}{*}{. } \\
\hline
\end{tabular}

Table 1 shows that, Out of 180 cases of hypertensive disorders of pregnancy, majority were of preeclampsia (47.22\%), then Gestational hypertension $(38.88 \%)$, eclampsia $(13.88 \%)$. Incidence of Pregnancy Induced Hypertension was $(5.97 \%)$.

Table No. 2: Risk factors Associated with Pregnancy induced Hypertension.

\begin{tabular}{|c|c|c|c|c|c|c|c|c|}
\hline \multirow{2}{*}{ Risk factors } & \multicolumn{2}{|c|}{ GSHT (n=70) } & \multicolumn{2}{l|}{ PREECLAMPSIA (n=85) } & \multicolumn{2}{c|}{ ECLAMPSIA (n - 25) } & Total (n=180) \\
\cline { 2 - 10 } & No & $\mathbf{\%}$ & No & \% & No & \% & No & \% \\
\hline Primi & 30 & 42.8 & 41 & 48.2 & 17 & 68 & 88 & 48.5 \\
\hline Age $>22 y$ & 21 & 30 & 42 & 49.4 & 3 & 12 & 66 & 36.66 \\
\hline Age $>35 y$ & 0 & & 4 & 4.7 & 9 & 36 & 13 & 7.22 \\
\hline H/o Previous Neonatal loss & 5 & 7.14 & 7 & 8.2 & 3 & 12 & 15 & 8.33 \\
\hline
\end{tabular}

Table-2 shows that most of the mothers with hypertensive disease were Primi $(48.5 \%) \&$ were age $<22 \%(36.66 \%)$. Whereas with age $>35 y$ rs only $7.22 \%$ have hypertension. About $8.3 \%$ mothers have previous bad obstetric history.

Table No. 3: Neonatal \& Perinatal Out come in PIH according to Low Birth weight, Prematurity, IUGR, Still Birth, Early Neonatal Death \& PMR.

\begin{tabular}{|c|c|c|c|c|c|c|c|c|c|c|c|}
\hline \multirow[t]{2}{*}{ Out come } & \multicolumn{2}{|c|}{$\begin{array}{c}\text { Gestational } \\
\text { Hyper- tension } \\
(n=70)\end{array}$} & \multicolumn{2}{|c|}{$\begin{array}{l}\text { Preeclampsia } \\
\qquad(\mathrm{n}=\mathbf{8 5})\end{array}$} & \multicolumn{2}{|c|}{$\begin{array}{c}\text { Eclampsia } \\
(n=25)\end{array}$} & \multicolumn{2}{|c|}{$\begin{array}{c}\text { Total } \\
(\mathrm{n}=\mathbf{1 8 0})\end{array}$} & \multicolumn{2}{|c|}{$\begin{array}{l}\text { Control } \\
(n=100)\end{array}$} & \multirow[t]{2}{*}{ P-value } \\
\hline & No & $\%$ & No & $\%$ & No & $\%$ & No & $\%$ & No & $\%$ & \\
\hline LBW & 29 & 41.4 & 53 & 62 & 22 & 88 & 104 & 57.7 & 22 & 22 & $<0.001 * *$ \\
\hline Prematurity & 16 & 22.8 & 44 & 51.7 & 20 & 80 & 80 & 44.4 & 18 & 18 & $<0.001 * *$ \\
\hline IUGR & 7 & 10 & 26 & 30 & 3 & 12 & 36 & 20.4 & 06 & 6 & $<0.05^{*}$ \\
\hline Still Birth & 1 & 1.4 & 4 & 4.7 & 3 & 12 & 8 & 4.4 & 1 & 1 & - \\
\hline Early N D & 2 & 2.8 & 10 & 11.76 & 10 & 40 & 22 & 12.2 & 3 & 3 & - \\
\hline PMR & \multicolumn{2}{|c|}{$43 / 1000$} & \multicolumn{2}{|c|}{$164 / 1000$} & \multicolumn{2}{|c|}{$520 / 1000$} & \multicolumn{2}{|c|}{$166 / 1000$} & \multicolumn{2}{|c|}{$40 / 1000$} & $\mathrm{P}<0.001^{*}$ \\
\hline
\end{tabular}


Table- 3 Shows Incidence of low birth weight in PIH is 57.7\%, preterm 44.2\% and IUGR 20.4\%, Still birth 8 (4.4\%), early neonatal death 22 (12.2\%), Highest incidence of LBW (88\%), Preterm (80\%), IUGR (12\%) is present in eclampsia group. In control group incidence of LBW is $22 \%(\mathrm{P}<.001)^{* *}$, Prmaturity-18\% $(\mathrm{P}<.001)^{* *}$, IUGR-6\% $\mathrm{P}(<.05)^{*}$. The perinatal mortality rate in $\mathrm{PIH}$ is $166 / 1000$ \& in control group is $40 / 1000$. $(\mathrm{P}<.001) * *$ highly significant.

Table-4: Distribution of Morbidities in PIH.

\begin{tabular}{|c|c|c|c|c|c|c|c|c|c|c|}
\hline \multirow[t]{2}{*}{ Morbidities } & \multicolumn{2}{|c|}{$\begin{array}{c}\text { Gestational } \\
\text { Hypertension } 69\end{array}$} & \multicolumn{2}{|c|}{$\begin{array}{c}\text { Preeclampsia } \\
(\mathbf{8 1})\end{array}$} & \multicolumn{2}{|c|}{ Eclampsia (22) } & \multicolumn{2}{|c|}{$\begin{array}{l}\text { Total } \\
(173)\end{array}$} & \multicolumn{2}{|c|}{$\begin{array}{c}\text { Control } \\
(100)\end{array}$} \\
\hline & No & $\%$ & No & $\%$ & No & $\%$ & No & $\%$ & No & $\%$ \\
\hline Birth Asphyxia & 15 & 21.7 & 28 & 34.5 & 18 & 81.8 & 61 & 35.2 & 10 & 10 \\
\hline HIE & 2 & 2.8 & 4 & 4.9 & 5 & 22.7 & 11 & 6.35 & 2 & 2 \\
\hline Septicemia & 15 & 21.7 & 14 & 17.2 & 12 & 54.5 & 41 & 23.6 & 8 & 8 \\
\hline Meningitis & 1 & 1.7 & 5 & 6.17 & 1 & 4.5 & 7 & 4 & - & - \\
\hline RDS & 1 & - & 2 & 2.4 & 1 & 4.5 & 4 & 2.3 & 1 & 1 \\
\hline $\mathrm{IVH}$ & 1 & 1.4 & 4 & 4.9 & 3 & 13.6 & 8 & 14.6 & - & - \\
\hline NNHB & 12 & 17.3 & 10 & 12.3 & 12 & 54.5 & 34 & 14.6 & 5 & 5 \\
\hline CHD & - & - & 1 & 1.2 & - & - & 2 & 11.5 & - & \\
\hline TOF & - & - & - & - & 1 & 4.5 & & & & \\
\hline
\end{tabular}

Table 4 shows that out of total 173 live births in PIH, 61 (35.26\%) suffered from Birth Asphyxia. Out of which 6.35\% developed HIE. Incidence of septicemia is $23.6 \%$, NNHB is $19.6 \%$.

Meningitis 4\%, IVH in $14.6 \%$. Percetage of Birth asphyxia is highest $81.8 \%$ in Eclampsia. Major morbidity in PIH is Birth Asphyxia \& septicemia.

\section{Discussion}

Out of total 3015 deliveries in the hospital, 180 (5.97\%) were found to have PIH, Majority of them were due to preeclampsia (47.2\%), gestational hypertension (38.8\%) and eclampsia (13.8\%).

Incidence of maternal hypertension in he present study is comparable with previous studies [10-13] Deorari [12] et al in his study reported preeclampsia 79\%, eclampsia 9.5\%. J Nadkarni [15] et al in 2001 found preeclampsia $50.4 \%$, eclampsia $10.6 \%$.

Hypertension disorder in pregnancy predisposes women to acute and chronic utero-placental insufficiency resulting in ante or intrapartum anoxia that may lead to fetal death, IUGR and preterm delivery [15].

In the present study, the percentage of LBW infants in $\mathrm{PIH}$ is $57.7 \%$, percentage of LBW infants in preeclampsia is $62 \%$ and in eclampsia is $88 \%$, while in gestational hypertension it is $41.4 \%$. Deorari [12] et al found $\mathrm{LBW}$ in $45.2 \%$ in preeclampsia and $70 \%$ in eclampsia. In the present study, the percentage of LBW infants in 100 control cases was $22 \%(\mathrm{P}<0.0001)$.

In the present study, total prematurity in $\mathrm{PIH}$ cases was $44.2 \%$. High incidence of prematurity is seen in eclampsia and it is the main cause of poor perinatal outcome. In the present study, the incidence of prematurity in 100 control cases was $18 \%(\mathrm{P}<0.0001)$. Similar findings were observed in the studies conducted by Chinchu et al and Sibai et al $[15,16]$.

IUGR in present study is $20.4 \%$ in PIH. In gestational hypertension IUGR is seen in $10 \%$, in preeclampsia $30 \%$ and in eclampsia $12 \%$. In the present study, the incidence of IUGR in 100 control cases was $6 \%(\mathrm{P}<$ 0.05). Similar findings were observed in the studies conducted by Chinchu et al [16] and Deorari et al [12].

In the present study, out of total 180 cases there were 8 (4.4\%) still births. Still birth rate was highest in eclampsia. Similarly, Yadav et al observed still birth rate of $4.8 \%$ in his study [13].

In the present study, overall perinatal mortality rate (PMR) in infants of mothers with hypertension is $166 / 1000$. PMR was highest (520/1000) in eclampsia. In the present study, the PMR in 100 control cases was 40/1000 ( $\mathrm{P}<0.001)$. Clifford et al [18] reported PMR of $400 / 1000$ in eclampsia in his study, whereas J Nadkarni [10] reported PMR of 159/1000 in eclampsia in his study. 
In the present study, birth asphyxia was seen in $35.2 \%$, septicemia in $23.6 \%$, respiratory distress syndrome (RDS) in $2.3 \%$, Hypoxic ischemic encephalopathy in $6.3 \%$, meningitis in $4 \%$. All the complications were more in eclampsia and preeclampsia group. Sibai et al [17] found $60 \%$ birth asphyxia in eclampsia, RDS in $27.5 \%$. Deodari ${ }^{11}$ et al found $21.7 \%$ birth asphyxia in eclampsia and $\mathrm{J}$ Nadkarni [15] found 14\% birth asphyxia, $7.5 \%$ sepsis, $7.3 \%$ RDS and $1.2 \%$ meningitis in eclampsia.

\section{Conclusion}

Prevention of prematurity, treatment of morbidities \& prevention of infection among infants should be done to reduce the PMR and improve perinatal outcome. The purpose of this article is to give overview of burden of adverse perinatal outcome in high risk Pregnancy. Thus High risk pregnancy should be identified prospectively and then given special care, perhaps a major impact on overall perinatal loss could be reduced.

\section{Funding: Nil, Conflict of interest: Nil \\ Permission from IRB: Yes}

\section{References}

1. S. Caritis, B. Sibai, J. Hauth et al. Predictors of preeclampsia in women at high risk. National Institute of Child Health and Human Development Network of Maternal-Fetal Medicine Units. American Journal of Obstetrics and Gynecology, vol. 179, no. 4, pp. 946951, 1998.

2. Douglas KA, Redman CW. Eclampsia in the United Kingdom. BMJ. 1994 Nov 26;309(6966):1395-400.

3. R. B. Ness and J. M. Roberts. Heterogeneous causes constituting the single syndrome of preeclampsia: a hypothesis and its implications. American Journal of Obstetrics and Gynecology, vol. 175, no. 5, pp. 13651370, 1996

4. Redman CW, Roberts JM. Management of preeclampsia. Lancet. 1993 Jun 5;341(8858):1451-4.

5. Chen XK, Wen SW, Smith G, Yang Q, Walker M. Pregnancy-induced hypertension is associated with lower infant mortality in preterm singletons. BJOG. 2006 May;113(5):544-51. Epub 2006 Mar 27.

6. Tranquilli AL, Giannubilo SR. The weight of fetal growth restriction in 437 hypertensive pregnancies.
Arch Gynecol Obstet. 2004 Dec;270(4):214-6. Epub 2003 Aug 27.

7. Cunningham FG, Mac Donald PC, Gant NF, Leveno KJ, Gilstrap LC, Hankins GDV, Clark SL. Distúrbios hipertensivos na gravidez. In: Cunningham FG, Mac Donald PC, Gant NF, Leveno KJ, Gilstrap LC, Hankins GDV, Clark SLTranquilli AL, Giannubilo SR. The 'weight' of foetal growth restriction in 437.

8. Wagner LK. Diagnosis and management of preeclampsia. Am Fam Physician. 2004 Dec 15; 70 (12):2317-24.

9. Sibai BM. Diagnosis and management of gestational hypertension and preeclampsia. Obstet Gynecol. 2003 Jul;102(1):181-92.

10. Sibai BM, Caritis S, Hauth J; National Institute of Child Health and Human Development Maternal-Fetal Medicine Units Network. What we have learned about preeclampsia. Semin Perinatol. 2003 Jun;27(3):239-46.

11. Nesbitt RE Jr, Aubry RH. High-risk obstetrics. II. Value of semiobjective grading system in identifying the vulnerable group. Am J Obstet Gynecol. 1969 Apr 1;103(7):972-85.

12. Deorari AK, Arora NK, Paul VK, Singh M. Perinatal outcome in hypertensive disease of pregnancy. Indian Pediatr. 1985 Dec;22(12):877-81.

13. Yadav. S, Saxena et al: Hypertensive Disorder of Pregnancy and Perinatal outcome. Indian. J. Obs \& Gyne. 1997, 47(4): 322-330.

14. Gray PH, O'Callaghan MJ, Mohay HA, Burns YR, King JF. Maternal hypertension and neurodevelopmental outcome in very preterm infants. Arch Dis Child Fetal Neonatal Ed. 1998 Sep;79(2):F88-93.

15. Nadkarni J, Bahl J, Parekh P. Perinatal outcome in pregnancy associated hypertension. Indian Pediatr. $2001 \mathrm{Feb} ; 38(2): 174-8$.

16. Lin CC, Lindheimer MD, River P, Moawad AH. Fetal outcome in hypertensive disorders of pregnancy. Am J Obstet Gynecol. 1982 Feb 1;142(3):255-60.

17. Sibai BM, Anderson GD, Abdella TN, Mc Cubbin JH, Dilts PV Jr. Eclampsia. III. Neonatal outcome, growth, and development. Am J Obstet Gynecol. 1983 Jun 1;146(3):307-16. 
18. Clifford Sh. High-Risk Pregnancy. I. Prevention Of Prematurity The Sine Qua Non For Reduction In
Mental Retardation And Other Neurologic Disorders. N Engl J Med. 1964 Jul 30;271:243-9.

\section{How to cite this article?}

Tiwari A, Dwivedi R. A study to evaluate the perinatal outcome in pregnancy induced hypertension. Int J Pediatr Res.2016;3(6):472-476.doi:10.17511/ijpr.2016.i06.17. 